to his wide range of interests in scientific work and in affairs. Sir Arthur Eddington took as his subject the "Constitution of the Stars". He reminded the audience that the problem of the constitution of the stars was first set forth in a paper, with a somewhat strange and comprehensive title, published by Lane in 1869. Since then, many attempts have been made to compute the temperatures existing deep inside the huge celestial furnaces. Thus, in the case of the sun, whilst the measured temperature of the photosphere is six thousand degrees, the computed temperature at the centre is twenty million degrees. This central region is now considered to be constituted of swarms of protons and stripped atoms moving at speeds of hundreds of miles per second, of swarms of electrons moving at ten thousand miles per second, and an enormous quantity of $\mathrm{X}$-radiation which is mainly resfonsible for the permanent shape of the sun. Because of its nature, the energy of this radiation can only leak away slowly, by a stepping-down process.

OWING to excessive ionisation, the average mass per particle in the middle of the sun is only two units, unless a considerable quantity of hydrogen is present. We have to know the average mass per particle in order to calculate the temperature at the centre. Sir Arthur said that he first made a reservation concerning the effect of hydrogen in 1927. It is now possible to measure the mass and the absolute brightness of a star and to say with some degree of certainty how much hydrogen it contains. In 1934, a further reservation is necessary because of the discovery of the neutron, for if neutrons were present to the extent of five per cent in the constitution, the material heat of the sun would be rapidly lost by conduction. However, it is felt that the properties of neutrons are not yet sufficiently established to make predictions, and, in any event, they can probably only exist inside atomic nuclei when near the centre of the sun. Sir Arthur also discussed the significance of recent experiments on artificial disin. tegration, which suggest a means by which the energy of the sun is replenished, namely, by the absorption of protons in atomic nuclei. This means that the temperature of the centre cannot rise much above ten million degrees so long as appreciable amounts of hydrogen are present.

ReFERRING to the "gaseous mass" postulated in Lane's paper, Sir Arthur Eddington pointed our that the sun obeys laws deduced for perfect gases, because of the huge compressibility of the stripped atoms inside the furnace. Densities some thousands of times greater than that of the earth are thus possible, and, indeed, are actually found to exist, for example, in the case of the dark companion of Sirius. Moreover, an application of the Pauli exclusion principle shows that such extremely dense matter must be cold, as is the companion of Sirius. Thus, although we seem farther away than ever from a solution of the problem of the evolution of the universe, Sir Arthur suggested that, since we are now able to formulate problems which were not even suspected ten years ago, we can more adequately measure our progress by the problems we are able to present for solution rather than by those we are able to solve.

\section{Oil from Coal in Great Britain}

Ors from coal was the subject of a debate in the House of Commons on February 8, when the British Hydrocarbon Oils Production Bill was read for the second time. The Bill proposes to give a preference of $4 d .-9 d$. a gallon on oil derived from British coal, peat and shale. The exact amount of the preference will depend on the customs duty payable on imported material, or on the difference between it and any excise duty. The duration of the preference will depend on its amount: at the minimum rate of $4 d$. a gallon it will operate for nine years, or, at $9 d$. a gallon, for four years. The Secretary for Mines (Mr. E. Brown) reported that the Government announce. ment of policy has already been followed by industrial developments. Imperial Chemical Industries have started the erection of a plant at Billingham for the annual production of 100,000 tons $(30,000,000$ gallons) of motor spirit by the hydrogenation of coal. A substantial increase is also shown in the amount of benzol obtained last year from gas works and coke ovens, as well as in the quantity of motor spirit from shale oil and low temperature carbonisation processes. More than 10,000 men have been put into employment already in connexion with the Billingham plant, and, in operation, it will absorb 1,280 men, and, in addition, some 1,200 miners for the production of 350,000 tons of coal a year. The actual cost to the Treasury of the production of 100,000 tons of oil under the new preference will, it is estimated, be about $£ 1,000,000$.

\section{Economic Issues in Hydrogenation}

The debate on the Bill referred to above brought forward a number of criticisms of the scheme. The opinion was voiced that the enterprise should be State-owned and directed, and also that the developments should be planned so as to assist the more depressed mining areas. It was also pointed out that hydrogenation has been in progress for a number of years in Germany, where very cheap lignite is available. In spite of a similar preference granted in that country, the synthetic petrol manufactured there in 1933 was less than the amount which is to be produced in Great Britain under the new scheme. Both the technical and the economic success of the process were, in fact, questioned. The motor-car industry is also faced with developments in heavy-oil engines of the Diesel type, which may in time displace light-oil engines and lessen the demand for petrol. A strong case was put forward, however, for the founding of this new industry as a means of utilising British coal resources more efficiently, and also for the covering of the requirements of national defence.

\section{Research on Foul Brood Diseases of Bres}

$\mathrm{Bx}$ co-operation between the bee keepers of England and the Agricultural Research Council, 
financial arrangements have been made to carry out at the Rothamsted Experimental Station, an investigation of foul brood diseases of bees, which have hitherto caused considerable trouble and loss. Dr. H. L. A. Tarr has been appointed investigator. Dr. Tarr is a graduate of the University of British Columbia and McGill University, and since 1931 he has been working at bacteriological problems in the Biochemical School at the University of Cambridge. Foul brood diseases were investigated in England nearly fifty years ago by Cheshire and Cheyne, and in more recent years by workers in the United States, Canada and on the Continent, but in spite of all that has been done, little is known about the cause of the diseases and still less as to how to avoid or cure them. The bee keepers, through the British Bee Keepers Association, have now agreed to raise half the money necessary for the investigations, and the Agricultural Research Council has undertaken to contribute the other half. As a result, a sum of $£ 500$ a year is now available for the study of foul brood. It is hoped that the work will continue for a period of at least three years, starting early in March 1934 under the general direction of Dr. C. B. Williams, head of the Department of Entomology at Rothamsted, with the co-operation of Mr. D. M. T. Morland, apiarist. Some of the more purely bacteriological side of the work will be carried out at the Lister Institute in London. Rothamsted Experimental Station will be advised on the practical side of the work by a small expert committee of bee keepers. Further contributions towards the cost of the investigations will be welcome.

\section{National Importance of Scientific Research}

REVIEwING the organisation of industrial research in Great Britain and other countries in an article in the Draughtsman of December entitled "Research and Industry", Mr. G. Windred concludes that we are at present by no means in a leading position, due perhaps to the curtailment of research expenditure in almost every direction, consequent upon the reduction of Government expenditure and the unwillingness of commercial organisations to spend capital. Mr. Windred states that industry, as a whole, is not prepared to apply scientific research methods until their possibilities have been clearly demonstrated. "Such demonstration can be effected only with the aid of research experience which must involve considerable expenditure, such as other countries have in general been willing to provide". The author reminds us that in the various departments of pure science, Great Britain holds a premier position which must prove of great assistance in the work of applying scientific principles to industrial improvement, and pleads for increased opportunities for industrial research. Assuredly, in this era of world-wide industrial progress, we can no longer afford to suffer the accusation that, however important are our fundamental discoveries in pure science, we yield pride of place to others in their application.

Public interest in the national importance of scientific research has recently been stimulated in Germany by a series of publications which are intended to awaken all classes to a realisation of the material benefits involved, and to counteract the tendency for too stringent economy in scientific work. These publications, which are written in nontechnical language, are sponsored by scientific and educational associations of high standing. In the United States there are said to be more than 1,500 well-established research organisations, and the expenditure of American industry in support of these research laboratories has been assessed for the year 1931 at no less than 235 million dollars. The activities of the Mellon Institute of Industrial Research of the University of Pittsburgh are too well known and appreciated in Great Britain to require more than a passing reference. As regards Russia, Mr. Windred has no doubt that the plans for scientific reconstruction in that country have the strongest scientific arguments in their favour. He devotes considerable attention to the work of the British Science Guild, which was founded in 1905 by Sir Norman Lockyer. The following statement, which the Guild has included in the announcement of its aims, objects and activities, is so manifestly pertinent to the conditions of to-day that it deserves the widest possible publicity : "The most urgent practical need to-day is the promotion of the spirit of unity among all classes through the alliance of Science, Invention and Labour, working as a single force for national development and common welfare. Science discovers; Invention applies; Industry produces. No nation can occupy a place in the van of modern civilisation unless the three legs of this tripod form strong and secure supports for all its constructive activities".

\section{Recent Advances in Microscopy}

Mr. Conrad BeCK, in his presidential address to the Royal Microscopical Society on January 17, pointed out that the resolution of the microscope had reached at least 100,000 lines to the inch in the middle of last century, and this limit was extended by steady advances to nearly 140,000 by the end of the century, but the limit is now placed at a figure that is less than $1 / 300,000 \mathrm{in.}$ In referring to dark ground illumination, he stated that while it was used with low and moderate powers almost from the time achromatic microscopes were first made, it is only in recent years that the refined apparatus required to use it with high power lenses has been produced. He remarked that this technique does not render differential staining less important and expressed his satisfaction that the Council of the Society has appointed a committee to study the stains and reagents used for microscopic research, and he suggested that, in addition to other matters, consideration should be given to the introduction of differential stains, particularly designed for dark ground illumination. As an example, he cited the anthrax bacillus which, stained with methylene blue, appears bloodred by dark ground, and hence there might be stains which would differentiate structure viewed by this means to a greater extent than can be done with transmitted light. 